\title{
Antibacterial and Degradable Thioimidazolium Poly(ionic liquid)
}

\author{
Christene Anne Smith, Vincenzo Alessandro Cataldo, Thomas Dimke, Ina Stephan, \\ and Ryan Guterman*
}

Cite This: ACS Sustainable Chem. Eng. 2020, 8, 8419-8424

Read Online

ACCESS

山ll Metrics \& More

Article Recommendations

Supporting Information

ABSTRACT: New antibacterial agents are urgently required to fight the emergence of antibiotic-resistant bacteria. We recently synthesized the first thioimidazolium ionene, which has antibacterial properties and can degrade in various media. This dual functionality is crucial in order to limit the environmental impact of these biocides. We have found that our polymer is stronger than benzalkonium chloride (BAC)

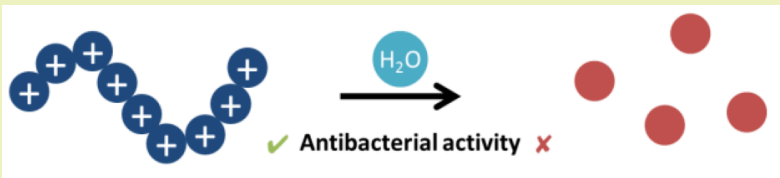

Thioimidazolium PIL

Degradation Product against Pseudomonas aeruginosa and also readily degrades in the presence of base, while remaining stable in acidic environments. These results highlight a new emerging class of antibacterial degradable polymers.

KEYWORDS: Antibacterial polymer, Amphiphilic polymer, Thioimidazolium, Degradable polymer, Polyioinic liquid, Ionic liquid

\section{INTRODUCTION}

The rise of antibiotic resistant bacteria from the misuse and overuse of antibiotics is increasingly a major global concern for all humans, animals, and plants. New strategies to combat these resistant bacteria are required in order to reduce bacterial infections worldwide. If alternatives are not found, then we risk returning to an era without antibiotics, warns the World Health Organization. ${ }^{1}$ In the 2019 Antibiotic Resistance Threats report, researchers found that over 2.8 million infections and 35,000 deaths occur yearly due to antibiotic resistance bacteria in the United States alone, which highlights the severity of this issue. ${ }^{2}$ Healthcare associated infections (HAIs) are one major source of antibiotic resistance infections. ${ }^{3}$ Those in hospitals are already more prone to infection than the general population due to their lowered immune system. Therefore, in order to prevent the infection of this at-risk population and limit the spread of antibiotic resistant bacteria, precautions must be enforced in high risk areas such as hospitals. The prevention of the initial spread of bacteria via adequate disinfection is believed to be the leading approach to mitigate infection and antibiotic use.

Traditional antibiotics and biocides are low molecular weight compounds that, while effective, are susceptible to resistance by bacteria. One common class of disinfectants are quaternary ammonium compounds (QACs), such as benzalkonium chloride (BAC), a well-known biocide. ${ }^{4-6}$ Unfortunately, some biocides, such as QACs, also have accumulation issues and have been found in sediments and biosoils worldwide. $^{7,8}$ BAC-resistant bacteria are known, and BAC used as a widespread biocide will not be effective in the long term. ${ }^{9}$ One way to increase biocidal activity and prevent the emergence of resistant bacteria is to integrate QACs into polymeric structures. ${ }^{10}$ This approach not only decreases the likelihood of bacterial resistance but also increases the efficacy of the material. The increase in antimicrobial efficiency in polymeric QACs compared to molecular variants is due to the increase in positive charge density and macroscopic character of the polymer. ${ }^{11}$ Antimicrobial polymer QACs operate on the basis of a membrane disruption mechanism similar to QACs. ${ }^{12,13}$ Increases in charge density and attachment points in polymeric QACs improve binding to the negatively charged bacterium membrane, which causes rupture of the cell membrane and cell death, leading to more effective biocides. $^{14,15}$

Amphiphilicity is another characteristic that is beneficial to ensure permeation of the polymer through the lipid bilayer at the bacterium membrane. ${ }^{16}$ Several amphiphilic polymeric structures have been investigated for antibacterial activity already, such as polyamides, ${ }^{17}$ polyphosphoniums, ${ }^{18,19}$ and polymethacrylates. $^{20,21}$ One way to achieve amphiphilic properties in polymers is using polyionic liquids (PILs), which contain charged species and may also include hydrophobic backbones, cross-linkers, or pendant groups. ${ }^{22}$ The Mao and Yan groups have shown that PILs with high cation density and long alkyl chains were more powerful biocides than their small molecule counterparts. ${ }^{23}$

Polymer waste and accumulation is one major drawback to their use as biocides. Due to their poor degradability, they are mainly used in the areas of fabricating coatings, films, and membranes, which benefit from stability. Thus, in order to

Received: April 8, 2020

Published: May 13, 2020 
have materials that do not accumulate and remain in our ecosystem long after their use, their degradability must be accessed. Ideally, cationic polymer biocides retain their antibacterial activity but degrade after their useful lifetime.

Recently, our group has discovered thioimidazolium-based biocides that slowly degrade in water via hydrolysis to form benign products $^{24,25}$ (Figure 1). The ability to hydrolyze these

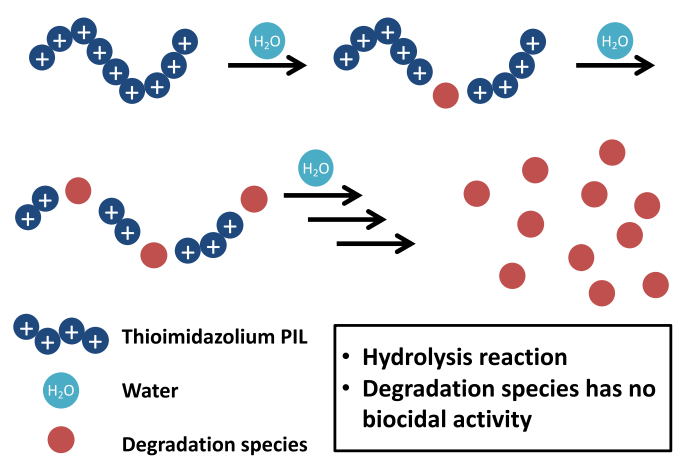

Figure 1. Degradable polyionic liquid (PIL) to uncharged species.

compounds under relatively mild conditions may provide a solution to prevent accumulation of biocides in the ecosystem. When they are incorporated into polymers, it may also be possible to harness their hydrolytic instability to depolymerize them while eliminating their cationic charge, a feat yet to be accomplished for poly(ionic liquids). To date, there have been no reported polymers based on the thioimidazolium functional group. Herein, we will describe the first example of a degradable thioimidazolium PIL that is also an effective antibacterial agent. While Escherichia coli and Staphylococcus aureus are common bacteria to test antibacterial activity against, we decided to test against Pseudomonas aeruginosa as it is one of the top three highly antibiotic resistant bacteria of public concern reported by the WHO. ${ }^{26}$ It was also tested against our previously published thioimidazolium-based biocides, which allows for direct comparison between the two systems. ${ }^{24}$ Our polymer displays excellent antimicrobial properties against $P$. aeruginosa, while slowly degrading in water. We found that the rate of decomposition is related to the anions present in the solution with relative rates following the Hofmeister series. These findings indicate that hydrolysis is dependent on the ionic environment and likely polymer conformation in solution with some anions completely inhibiting the degradation process, thus providing the possibility for triggered decomposition. These materials are essential as an environmentally conscious response to the need for varied antibacterial treatments and will aid in the development of new biocides.

\section{RESULTS AND DISCUSSION}

When one designs a degradable antibacterial polymer, there are two aspects of the polymer to take into account. First, there must be some moiety responsible for cell death; known antibiotics, biomolecules, and salts are frequently used. Second, there must be some moiety that will degrade in the environment after the antibacterial properties have been used. When designing our polymer, we considered both of these aspects. In particular, imidazolium polymer salts are frequently used, as they are relatively simple and low cost to synthesize. Despite their use, they suffer from high stability and do not easily degrade, which in the case of their polymer congeners poses significant environmental concerns. In contrast, thioimidazolium salts are less stable and thus are ideal candidates for degradable antibacterial polymers due to both their cationic nature, which should facilitate cell death, and labile cross-linking groups, which will easily degrade.

To synthesize our thioimidazolium polymer, first, 1,2-bis(2iodoethoxy)ethane was synthesized from 1,2-bis(2chloroethoxy)ethane by the Finkelstein reaction with sodium iodide in acetone (Figure 2(i)). Then, two equivalents of 1butyl imidazole were reacted with 1,2-bis(2-iodoethoxy)ethane to afford compound 1, a diimidazolium salt (Figure 2(ii)). This salt was then reacted with sulfur in order to produce a dithione, which was then derivatized into either our small

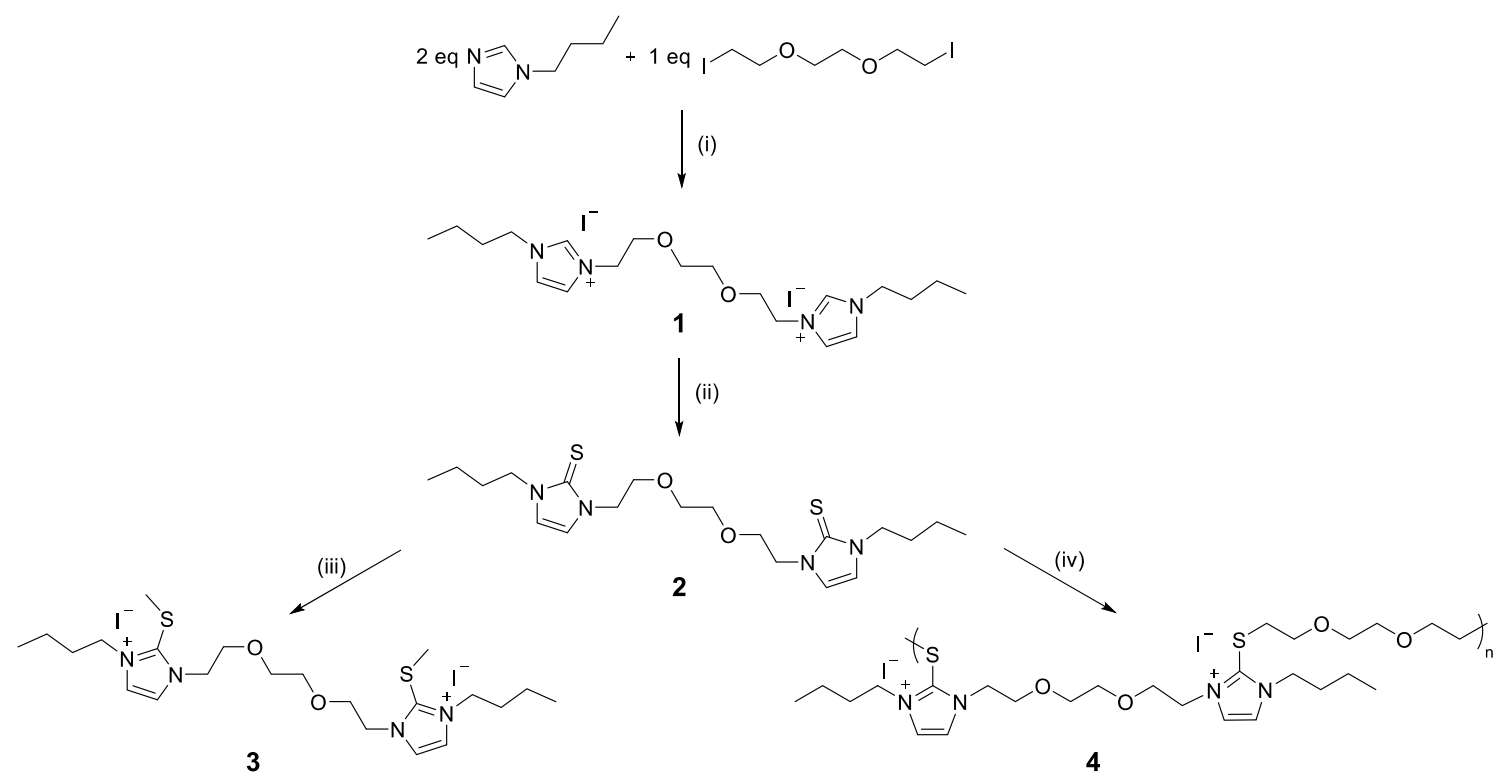

Figure 2. Synthesis of small molecule 3 and polymer 4. (i) $\mathrm{MeCN}, 90{ }^{\circ} \mathrm{C}, 18 \mathrm{~h}$; (ii) $\mathrm{K}_{2} \mathrm{CO}_{3}, \mathrm{~S}_{8}, \mathrm{MeOH}, 90{ }^{\circ} \mathrm{C}, 6$ days; (iii) DMF, MeI, RT, $18 \mathrm{~h}$; (iv) DMF, 1,2-bis (2-iodoethoxy)ethane, $65^{\circ} \mathrm{C}, 18 \mathrm{~h}$. 
molecule model compound 3 or our polymeric compound 4 . The small molecule model was synthesized by alkylating the sulfur atoms with methyl iodide to acquire the dithioimidazolium salt, 3 (Figure 2(iii)). The polymeric derivative was made by reacting 2 with 1,2-bis(2-iodoethoxy)ethane to obtain the thioimidazolium polymer 4 (Figure 2(iv)). All compounds were characterized by nuclear magnetic resonance spectroscopy $\left({ }^{1} \mathrm{H}\right.$ and $\left.{ }^{13} \mathrm{C}\left\{{ }^{1} \mathrm{H}\right\} \mathrm{NMR}\right)$ and mass spectroscopy (MS).

For polymer 4 , additional characterizations were completed to determine its molecular weight and polymeric properties. Since the synthesis of this ionene by an $\mathrm{S}_{\mathrm{n}} 2$ reaction is in fact reversible, a reaction temperature that is hot enough to promote high conversions yet will not result in dealkylation is critical. We found that a reaction temperature of $65^{\circ} \mathrm{C}$ was suitable for this purpose to obtain 4 with a $M_{\text {w }}$ of $5.56 \times 10^{4} \mathrm{~g} /$ mol. Conversely, only room temperature was necessary with methyl iodide to produce 3 .

When the polymer was designed, the characteristics of the linker and the functional groups on the imidazoliums were carefully examined. It has been reported that the polymeric properties of ionenes rely highly on that of the linker groups. ${ }^{27}$

Therefore, in order to obtain a polymer with hydrophilic properties, we selected a glycol linker for both between the imidazolium groups and between the sulfurs. To impart hydrophobic properties, butyl groups were selected to functionalize the imidazoliums. As this design is very modular, in the future, different linkers and nitrogen functional groups may be selected to alter the materials properties, which may affect its antimicrobial activity and degradability.

We explored the antimicrobial activity of our small molecule 3 and polymer 4 against Pseudomonas aeruginosa (Table 1),

Table 1. Quantitative Suspension Test for Antibacterial Activity (Pseudomonas aeruginosa) of 3 and 4 in Comparison to a Benzalkonium Chloride (BAC) Reference at Different Times

\begin{tabular}{ccccc} 
& & \multicolumn{3}{c}{$\begin{array}{c}\text { target reduction of } 5 \log _{10} \\
\text { cfu }\end{array}$} \\
\cline { 3 - 5 } substance & concentration (wt \%) & $5 \mathrm{~min}$ & $10 \mathrm{~min}$ & $30 \mathrm{~min}$ \\
small molecule (3) & $2.5 \times 10^{-3}$ & $\mathrm{~N}$ & $\mathrm{~N}$ & $\mathrm{~N}$ \\
& $2.0 \times 10^{-3}$ & $\mathrm{~N}$ & $\mathrm{~N}$ & $\mathrm{~N}$ \\
& $1.5 \times 10^{-3}$ & $\mathrm{~N}$ & $\mathrm{~N}$ & $\mathrm{~N}$ \\
polymer (4) & $1.0 \times 10^{-3}$ & $\mathrm{~N}$ & $\mathrm{~N}$ & $\mathrm{~N}$ \\
& $2.5 \times 10^{-3}$ & $\mathrm{Y}$ & $\mathrm{Y}$ & $\mathrm{Y}$ \\
BAC (reference) & $1.0 \times 10^{-3}$ & $\mathrm{Y}$ & $\mathrm{Y}$ & $\mathrm{Y}$ \\
& $5.0 \times 10^{-4}$ & $\mathrm{~N}$ & $\mathrm{~N}$ & $\mathrm{Y}$ \\
& $1.0 \times 10^{-2}$ & $\mathrm{Y}$ & $\mathrm{Y}$ & $\mathrm{Y}$ \\
\hline
\end{tabular}

which is a problematic bacterium to disinfect and has been found in relation to hospital-obtained infections. ${ }^{28,29}$ At all concentrations at which the small molecule (3) was tested $\left(2.5,2.0,1.5\right.$, and $\left.1.0 \times 10^{-3}\right)$, the threshold of a $5 \log _{10^{-}}$ reduction (lg) in colony-forming units (cfu) was never surpassed. In contrast, the polymer (4) was a significantly more powerful antibacterial agent able to achieve a $\lg$ of 5.2 after only $5 \mathrm{~min}$ of contact time at $1.0 \times 10^{-3} \mathrm{wt} \%$. Even at concentrations as low as $5.0 \times 10^{-4}$,a $\lg$ of 5.3 was observed with $30 \mathrm{~min}$ of contact time. These results show that our polymer is a suitable antibacterial candidate, as it meets the conditions imposed by EN1040, an evaluation for basic antibacterial activity for disinfectants and antiseptics.
In contrast, previous studies have found several cationic polymers tested to have minimum inhibitory concentrations (MICs) of $1.6-6.4 \times 10^{-2}$ wt $\%$ against the same bacteria. ${ }^{30,31}$ In one study, eight different cationic polymers were tested and none could surpass the efficacy of BAC; in many cases, they were well below BAC's activity. ${ }^{30}$ Xiong and co-workers recently synthesized antibacterial polyrotaxanes, and while they were not as effective as our polymer, they found that cell death was facilitated by binding and disrupting the cell wall. ${ }^{31}$ This shows that our thioimidazolium design is a more effective biocide than other common cationic polymers, and we can surmise that the mode of action is similar to other cationic polymers.

After a hydrolysis event and as the polymer depolymerizes to form degradation products (Figure $3 \mathrm{~b}$ ), the molecular weight of the polymer decreases and therefore should have reduced biocidal properties. In addition, the degradation of the polymer also eliminates the cationic thioimidazolium groups, which are responsible for the biocidal activity of the polymer. Therefore, the decrease in antimicrobial properties should be quite pronounced as the polymer degrades.

The antimicrobial activity of the decomposition products is important to consider. Here, the degradation products include alkyl thiols and thiolates, bisimidazolones, and mineral acids and salts (Figure 3b). Both alkylthiolates and mineral acids and salts are present in very low concentrations upon degradation and are not known to possess antimicrobial properties. Imidazolone and other related functional groups are known to be nontoxic and have uses as anticancer agents. ${ }^{32}$ Bisimidazoles, a related function group, have shown antimicrobial activities requiring orders of magnitude more material than our polymer against a variety of bacteria, ${ }^{33}$ while hydantoin-related compounds are shown to be good fertilizers. $^{34}$

To test the decomposition characteristics of our materials, we designed NMR and GPC studies to measure their decomposition over time (Figure 3). To determine \% decomposition, the integration of the protons on the imidazolone ring (Figure 3a, blue) was compared to that of the protons on the starting thiomidazolium ring to determine overall decomposition. These peaks were chosen as they are relatively isolated from the rest of the spectrum and are characteristic to both the degradation product and the starting polymer 4 . We observed that the degradation rate is generally on the order of days (Figure 3c) or, in the case in basic media, hours (Figure 3d), which in both cases is much higher than the time scale for the antimicrobial experiments (up to $30 \mathrm{~min}$ ). This large difference ensures that the polymer is the active antimicrobial species present in solution and what is measured in these experiments. The stepwise degradation of the polymer likely follows that of other polymers, which degrade via hydrolysis. Others have found that a bimodal distribution in the observed $M_{\mathrm{w}}$ is seen initially; ${ }^{35}$ however, this eventually coalesces as complete degradation is obtained.

Polyelectrolytes are highly sensitive to ions within their environments and will change confirmation and behavior in solution. ${ }^{36}$ It was unknown as to whether such variables would affect the degradability of main-chain thioimidazolium polymers. Sodium chloride, sodium hydrogen carbonate, phosphate buffered saline (PBS), sodium hydroxide, sodium iodide, sodium perchlorate, and sulfuric acid were chosen as key conditions in order to test decomposition. Sodium chloride and phosphate buffered saline (PBS) were chosen 


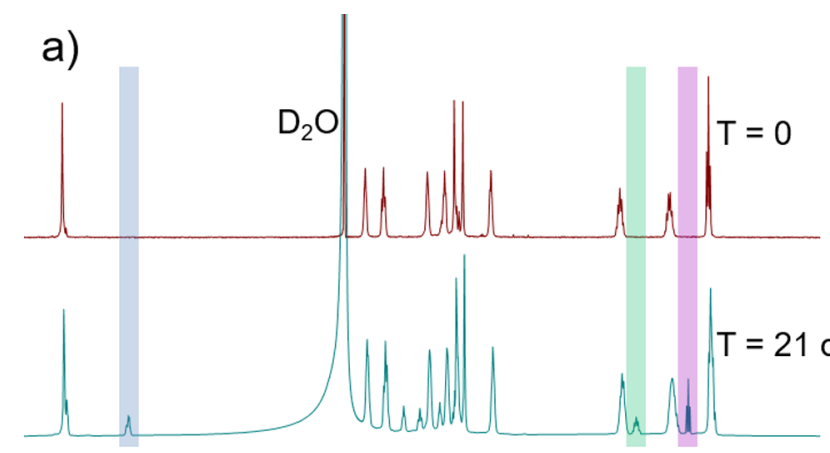

c)
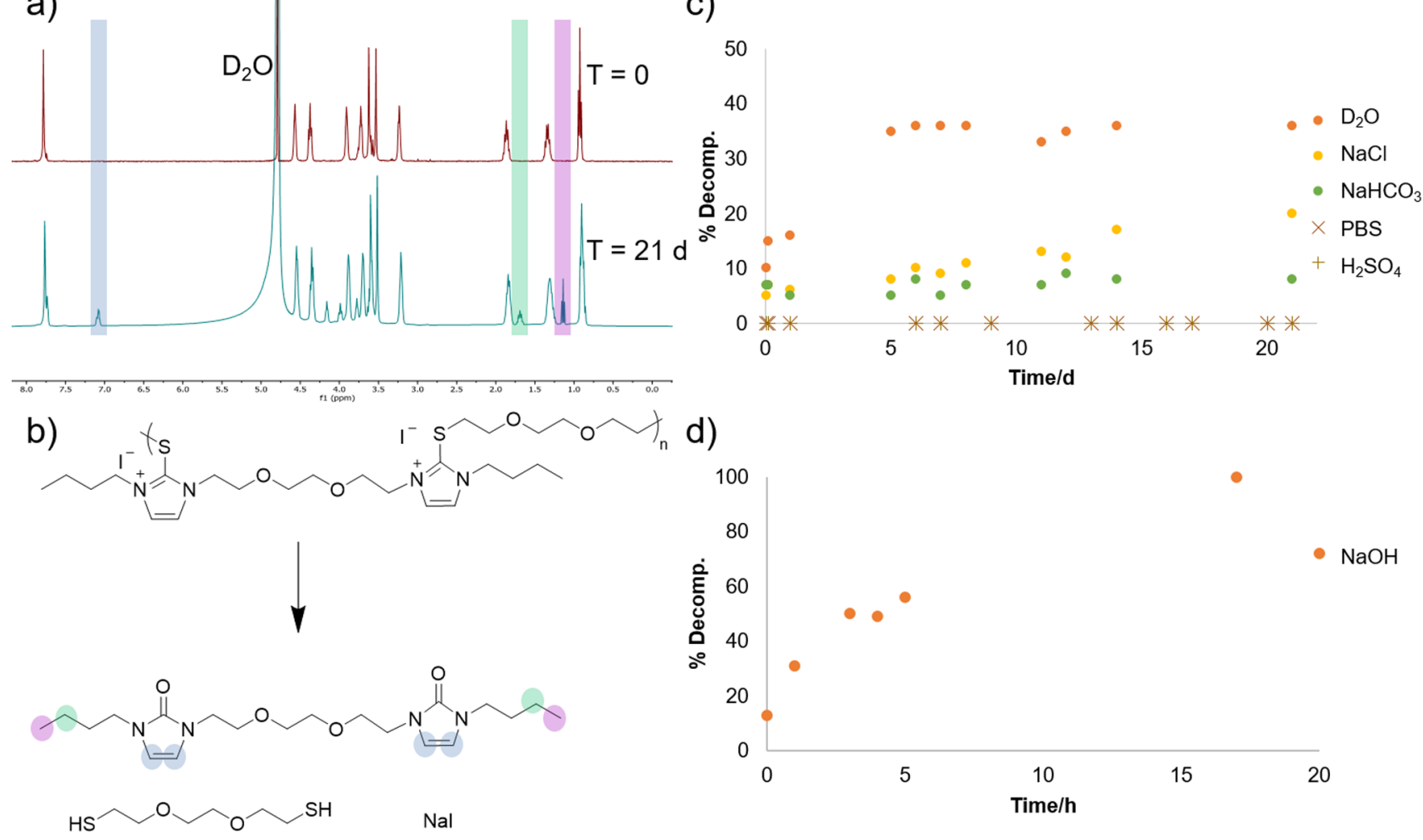

Figure 3. (a) NMR spectroscopy of the polymer degradation in $\mathrm{D}_{2} \mathrm{O}$ at $T=0$ and $T=21$ days. (b) Degradation of the polymer 1 to the imidazolone, thioether, and sodium iodide. (c) Decomposition kinetics of the polymer 1 in $\mathrm{D}_{2} \mathrm{O}, \mathrm{NaCl}, \mathrm{NaHCO}_{3}, \mathrm{PBS}$, and $\mathrm{H}_{2} \mathrm{SO}_{4}$. (d) Decomposition kinetics of the polymer in $\mathrm{NaOH}$.

as they are common species in marine and groundwater environments. They are therefore likely to be present when the polymer enters the environment after use. Sodium hydrogen carbonate, sodium hydroxide, and sulfuric acid were chosen to represent various $\mathrm{pH}$ regimes. Different $\mathrm{pH}$ environments are predicted to have large effects on decomposition on the basis of our proposed decomposition mechanism (Scheme S1). Lastly, sodium iodide and sodium perchlorate were chosen as they both are known to have strong effects in the Hofmeister series, which describes the effect that various ions can have on polymer solubility.

Solutions of $\mathbf{4}$ were prepared in deuterium oxide, and then, the corresponding salts were added to the solution. NMR spectra were taken at various intervals. In our 2018 report on thiomidazolium molecular degradable antiseptics, ${ }^{24}$ we found that thioimidazoliums degrade to imidazolones and thiol byproducts when exposed to $\mathrm{NaCl}, \mathrm{D}_{2} \mathrm{O}, \mathrm{NaHCO}_{3}$, and $\mathrm{NaOH}$. The same is true for these polymer materials. As expected, on the basis of our previous study, ${ }^{37}$ the polymer degraded most rapidly in a solution of sodium hydroxide $(0.2$ $\mathrm{M})$. After only $5 \mathrm{~h}, 56 \%$ of the starting polymer had degraded, and $100 \%$ degradation was observed after $17 \mathrm{~h}$. A solution of the polymer in pure $\mathrm{D}_{2} \mathrm{O}$ surprisingly showed the next fastest decomposition rate with over $36 \%$ of the starting polymer degrading during this time. Sodium chloride and sodium hydrogen carbonate $(0.2 \mathrm{M})$ showed $20 \%$ and $8 \%$ decomposition, respectively, during the same time period.

When $\mathrm{NaI}$ or $\mathrm{NaHClO}_{4}$ was added to a $\mathrm{D}_{2} \mathrm{O}$ solution of the polymer, immediate precipitation was observed. This can be explained using the Hofmeister series, which dictates that proteins and neutral polymers should have enhanced solubility in the presence of some cations when compared to others in the order of $\mathrm{SO}_{4}{ }^{2-}>\mathrm{HPO}_{4}{ }^{2-}>\mathrm{HCO}_{3}{ }^{-}>\mathrm{Cl}^{-}>\mathrm{Br}^{-}>\mathrm{I}^{-}>$ $\mathrm{ClO}_{4}{ }^{-38-41}$ For charged polymers, this order is switched and salting out is observed for $\mathrm{I}^{-}$and $\mathrm{ClO}_{4}^{-}$. It is also interesting in the case of $\mathrm{PBS}$ and $\mathrm{H}_{2} \mathrm{SO}_{4}$ that no decomposition is observed over the 21 day time span. In the case of $\mathrm{H}_{2} \mathrm{SO}_{4}$, the polymer remained stable with little to no degradation over a span of 21 days. This demonstrates that the polymer can withstand acidic environments and supports our proposed decomposition pathways that are accelerated in the presence of base (Scheme S1). The instability of thioimidazolium salts in the presence of base and other strong nucleophiles is well established and is often used to prepare guanidines. ${ }^{42}$ In the case of PBS, it was performed with a relatively low concentration $(10 \mathrm{mM}$ versus $0.2 \mathrm{M}$ of other solutions). To test whether the concentration of the buffer played a role in stability, an additional decomposition experiment was performed in 0.2 M PBS ( $\mathrm{pH} 7.25$ ) and no decomposition was observed after a 21 day period, similar to the $10 \mathrm{mM}$ PBS experiment. Therefore, it is surmised that the phosphate anion and neutral $\mathrm{pH}$ are responsible for the enhanced stability following the Hofmeister series.

After 28 days, the solubility of the sample appeared to change and, thus, the observed decomposition stagnated, as interactions with the solvent is required for decomposition. For this reason, the measurement of the decomposition under concentrated conditions proved difficult. Nonetheless, in alkaline conditions, solubility problems were avoided and complete degradation was observed, demonstrating that, when soluble, the polymer will hydrolyze. 
In order to confirm the loss of cationic charge of the polymer, Zeta potential measurements were conducted before and after degradation. Solutions of $\mathbf{3}$ and $\mathbf{4}$ were prepared in $\mathrm{D}_{2} \mathrm{O}$, and $\mathrm{NaOH}$ was added. Immediately thereafter, Zeta potential was measured on both samples, with potentials of $+21.32 \pm 0.64$ and $+15.05 \pm 0.40 \mathrm{mV}$ for 3 and 4 , respectively. Then, the solutions were heated at $80{ }^{\circ} \mathrm{C}$ for $1 \mathrm{~h}$, and Zeta potential, NMR, and HR-MS experiments were performed. NMR spectroscopy and HR-MS both confirmed the presence of the bisimidazolone shown in Figure $3 \mathrm{~b}$. The found $\mathrm{m} / \mathrm{z}$ of 398.2820 confirms the molecular weight and the characteristic imidazolone peak at $6.5 \mathrm{ppm}$ in the ${ }^{1} \mathrm{H}$ NMR spectrum (Figure S14), thus confirming degradation had taken place. The Zeta potentials for the degraded samples were measured to be $-12.4 \pm 1.4$ and $-25.6 \pm 0.9 \mathrm{mV}$ for 3 and 4 , respectively, indicating that the polymer has degraded. Discrepancies between the two can be explained by the different thioether side products that would arise in either reaction.

\section{CONCLUSIONS}

A thioimidazolium PIL and small molecule were synthesized for the first time. We found that PIL 4 was an effective antibacterial agent that facilitated cell death at very low concentrations, while the small molecule 3 was unable to do so. This antibacterial material was also found to degrade in water at room temperature steadily over a span of 3 weeks and in sodium hydroxide over several hours, thus demonstrating for the first time a degradable PIL biocide that depolymerizes and loses its positive charge simultaneously. Unexpectedly, we found that the degradation of the polymer in the presence of different anions can be described using the Hofmeister series, which suggests that ionic environment and polymer conformation affects the hydrolysis rate. This feature can be used to adjust the degradation rate whereby degradation can be completely inhibited in solutions containing phosphate and increased in the presence of chloride anions or pure water. The ability to harness the improved biocidal activity of cation polymer structures with depolymerization and deionization simultaneously provides a new paradigm to design biocides that are both effective and environmentally friendly. Different polymer designs with other linkers and alkyl groups will be examined in the future in order to synthesize more powerful antibacterial agents that are able to more rapidly degrade under milder conditions. Finally, a better understanding of the decomposition mechanism in the presence of different ions is needed in order to smartly design these polymers for practical antimicrobial applications.

\section{ASSOCIATED CONTENT}

\section{SI Supporting Information}

The Supporting Information is available free of charge at https://pubs.acs.org/doi/10.1021/acssuschemeng.0c02666.

Experimental details, synthetic procedure, antibacterial experimental method and data, and characterization data (PDF)

\section{AUTHOR INFORMATION}

\section{Corresponding Author}

Ryan Guterman - Department of Colloid Chemistry, Max Planck Institute for Colloids and Interfaces, 14476 Potsdam, Germany; ○ orcid.org/0000-0003-3231-6176; Email: ryan.guterman@mpikg.mpg.de

\section{Authors}

Christene Anne Smith - Department of Colloid Chemistry, Max Planck Institute for Colloids and Interfaces, 14476 Potsdam, Germany

Vincenzo Alessandro Cataldo - Department of Colloid Chemistry, Max Planck Institute for Colloids and Interfaces, 14476 Potsdam, Germany; (1) orcid.org/0000-0003-49458496

Thomas Dimke - Bundesanstalt für Materialforschung und-prüfung (BAM), 12205 Berlin, Germany

Ina Stephan - Bundesanstalt für Materialforschung und-prüfung (BAM), 12205 Berlin, Germany

Complete contact information is available at: https://pubs.acs.org/10.1021/acssuschemeng.0c02666

\section{Author Contributions}

The manuscript was written through contributions of all authors.

\section{Notes}

The authors declare no competing financial interest.

\section{ACKNOWLEDGMENTS}

We thank the Max Planck Society for their ongoing support. We thank the members of Bundesanstalt für Materialforschung und-prüfung (BAM) for their productive discussions. We thank Ursula Lubahn for her assistance with data management, Antje Völkel for her assistance with the DSC, TGA, and AUC measurements, and Marlies Gräwert for her assistance with the GPC measurements. We thank Markus Antonietti for his fruitful discussions, ongoing support, wisdom, and lead vocals.

\section{REFERENCES}

(1) WHO Global action plan on antimicrobial resistance, https:// www.who.int/antimicrobial-resistance/global-action-plan/en/ (accessed 2019-11-13).

(2) CDC. Antibiotic Resistance Threats in the United States; CDC: Atlanta, GA, 2019.

(3) Weiner, L. M.; Fridkin, S. K.; Aponte-Torres, Z.; Avery, L.; Coffin, N.; Dudeck, M. A.; Edwards, J. R.; Jernigan, J. A.; Konnor, R.; Soe, M. M.; et al. Vital Signs: Preventing Antibiotic-Resistant Infections in Hospitals - United States, 2014. Am. J. Transplant. 2016, 16 (7), 2224-2230.

(4) Buffet-Bataillon, S.; Tattevin, P.; Bonnaure-Mallet, M.; JolivetGougeon, A. Emergence of Resistance to Antibacterial Agents: The Role of Quaternary Ammonium Compounds-a Critical Review. Int. J. Antimicrob. Agents 2012, 39 (5), 381-389.

(5) Brycki, B. E.; Kowalczyk, I. H.; Szulc, A. M.; Brycka, J. A. Quaternary Alkylammonium Salts as Cleaning and Disinfectant Agents. Tenside, Surfactants, Deterg. 2018, 55 (6), 432-438.

(6) Domagk, G. Eine neue Klasse von Desinfektionsmitteln. Dtsch. Med. Wochenschr. 1935, 61 (21), 829-832.

(7) Dai, X.; Wang, C.; Lam, J. C. W.; Yamashita, N.; Yamazaki, E.; Horii, Y.; Chen, W.; Li, X. Accumulation of Quaternary Ammonium Compounds as Emerging Contaminants in Sediments Collected from the Pearl River Estuary, China and Tokyo Bay, Japan. Mar. Pollut. Bull. 2018, 136, 276-281.

(8) Clarke, B. O.; Smith, S. R. Review of 'Emerging' Organic Contaminants in Biosolids and Assessment of International Research Priorities for the Agricultural Use of Biosolids. Environ. Int. 2011, 37 (1), 226-247.

(9) Korsak, D.; Chmielowska, C.; Szuplewska, M.; Bartosik, D. Prevalence of Plasmid-Borne Benzalkonium Chloride Resistance Cassette BcrABC and Cadmium Resistance CadA Genes in Nonpathogenic Listeria Spp. Isolated from Food and Food-Processing Environments. Int. J. Food Microbiol. 2019, 290, 247-253. 
(10) Xue, Y.; Xiao, H.; Zhang, Y. Antimicrobial Polymeric Materials with Quaternary Ammonium and Phosphonium Salts. Int. J. Mol. Sci. 2015, 16, 3626.

(11) Timofeeva, L.; Kleshcheva, N. Antimicrobial Polymers: Mechanism of Action, Factors of Activity, and Applications. Appl. Microbiol. Biotechnol. 2011, 89 (3), 475-492.

(12) Lou, W.; Venkataraman, S.; Zhong, G.; Ding, B.; Tan, J. P. K.; Xu, L.; Fan, W.; Yang, Y. Y. Antimicrobial Polymers as Therapeutics for Treatment of Multidrug-Resistant Klebsiella Pneumoniae Lung Infection. Acta Biomater. 2018, 78, 78-88.

(13) Gilbert, P.; Moore, L. E. Cationic Antiseptics: Diversity of Action under a Common Epithet. J. Appl. Microbiol. 2005, 99 (4), $703-715$.

(14) Lu, G.; Wu, D.; Fu, R. Studies on the Synthesis and Antibacterial Activities of Polymeric Quaternary Ammonium Salts from Dimethylaminoethyl Methacrylate. React. Funct. Polym. 2007, 67 (4), 355-366

(15) Campoccia, D.; Montanaro, L.; Arciola, C. R. A Review of the Biomaterials Technologies for Infection-Resistant Surfaces. Biomaterials 2013, 34 (34), 8533-8554.

(16) Santos, M. R. E.; Mendonça, P. V.; Almeida, M. C.; Branco, R.; Serra, A. C.; Morais, P. V.; Coelho, J. F. J. Increasing the Antimicrobial Activity of Amphiphilic Cationic Copolymers by the Facile Synthesis of High Molecular Weight Stars by Supplemental Activator and Reducing Agent Atom Transfer Radical Polymerization. Biomacromolecules 2019, 20 (3), 1146-1156.

(17) Ahadian, S.; Sadeghian, R. B.; Salehi, S.; Ostrovidov, S.; Bae, H.; Ramalingam, M.; Khademhosseini, A. Bioconjugated Hydrogels for Tissue Engineering and Regenerative Medicine. Bioconjugate Chem. 2015, 26 (10), 1984-2001.

(18) Cuthbert, T. J.; Harrison, T. D.; Ragogna, J.; Gillies, E. R. Synthesis, Properties, and Antibacterial Activity of Polyphosphonium Semi-Interpenetrating Networks. J. Mater. Chem. B 2016, 4, 48724883.

(19) Cuthbert, T. J.; Hisey, B.; Harrison, T. D.; Trant, J. F.; Gillies, E. R.; Ragogna, P. J. Surprising Antibacterial Activity and Selectivity of Hydrophilic Polyphosphoniums Featuring Sugar and Hydroxy Substituents. Angew. Chem., Int. Ed. 2018, 57 (39), 12707-12710.

(20) Hart, L. R.; Li, S.; Sturgess, C.; Wildman, R.; Jones, J. R.; Hayes, W. 3D Printing of Biocompatible Supramolecular Polymers and Their Composites. ACS Appl. Mater. Interfaces 2016, 8 (5), $3115-3122$.

(21) Yue, J.; Zhao, P.; Gerasimov, J. Y.; van de Lagemaat, M.; Grotenhuis, A.; Rustema-Abbing, M.; van der Mei, H. C.; Busscher, H. J.; Herrmann, A.; Ren, Y. 3D-Printable Antimicrobial Composite Resins. Adv. Funct. Mater. 2015, 25 (43), 6756-6767.

(22) Muñoz-Bonilla, A.; Fernández-García, M. Poly(Ionic Liquid)s as Antimicrobial Materials. Eur. Polym. J. 2018, 105, 135-149.

(23) Zheng, Z.; Xu, Q.; Guo, J.; Qin, J.; Mao, H.; Wang, B.; Yan, F. Structure-Antibacterial Activity Relationships of Imidazolium-Type Ionic Liquid Monomers, Poly(Ionic Liquids) and Poly(Ionic Liquid) Membranes: Effect of Alkyl Chain Length and Cations. ACS Appl. Mater. Interfaces 2016, 8 (20), 12684-12692.

(24) Miao, H.; Stephan, I.; Dimke, T.; Cataldo, V. A.; Antonietti, M.; Guterman, R. Thioimidazolium Salts as a Platform for Nonvolatile Alkylators and Degradable Antiseptics. ACS Sustainable Chem. Eng. 2018, 6 (11), 15434-15440.

(25) Guterman, R.; Miao, H.; Antonietti, M. Thioimidazolium Ionic Liquids as Tunable Alkylating Agents. J. Org. Chem. 2018, 83 (2), 684-689.

(26) WHO Global Priority List of Antibiotic-Resistant Batceria to Guide Research, Discovery, and Development of New Antibiotics; WHO: Geneva, 2017.

(27) Zhao, Q.; Shen, C.; Halloran, K. P.; Evans, C. M. Effect of Network Architecture and Linker Polarity on Ion Aggregation and Conductivity in Precise Polymerized Ionic Liquids. ACS Macro Lett. 2019, 8 (6), 658-663.

(28) Feretzakis, G.; Loupelis, E.; Sakagianni, A.; Skarmoutsou, N.; Michelidou, S.; Velentza, A.; Martsoukou, M.; Valakis, K.;
Petropoulou, S.; Koutalas, E. A 2-Year Single-Centre Audit on Antibiotic Resistance of Pseudomonas Aeruginosa, Acinetobacter Baumannii and Klebsiella Pneumoniae Strains from an Intensive Care Unit and Other Wards in a General Public Hospital in Greece. Antibiotics 2019, 8, 62.

(29) Sader, H. S.; Castanheira, M.; Streit, J. M.; Flamm, R. K. Frequency of Occurrence and Antimicrobial Susceptibility of Bacteria Isolated from Patients Hospitalized with Bloodstream Infections in United States Medical Centers (2015-2017). Diagn. Microbiol. Infect. Dis. 2019, 95 (3), 114850.

(30) Venkatesh, M.; Barathi, V. A.; Goh, E. T. L.; Anggara, R.; Fazil, M. H. U. T.; Ng, A. J. Y.; Harini, S.; Aung, T. T.; Fox, S. J.; Liu, S.; et al. Antimicrobial Activity and Cell Selectivity of Synthetic and Biosynthetic Cationic Polymers. Antimicrob. Agents Chemother. 2017, 61 (10), e00469-17.

(31) Qiao, J.; Liu, Z.; Purro, M.; Xiong, M. P. Antibacterial and Potentiation Properties of Charge-Optimized Polyrotaxanes for Combating Opportunistic Bacteria. J. Mater. Chem. B 2018, 6 (33), 5353-5361.

(32) Bock, M. G.; Gaul, C.; Gummadi, V. R.; Sengupta, S. 1,3Disubstituted Imidazolidin-2-One Derivatives as Inhibitors of Cyp 17, US 8263635 B2, 2010.

(33) Aonofriesei, F.; Lupsor, S. Inhibitory Potential of a Novel Imidazole Derivative as Evaluated by Time-Kill and Dehydrogenase Activity. Curr. Microbiol. 2013, 66 (2), 162-168.

(34) Shimizu, T. Studies on the Use of Hydantoin-Related Compounds as Slow Release Fertilizers. Soil Sci. Plant Nutr. 1986, 32 (3), 373-382.

(35) Rodriguez, E. J.; Marcos, B.; Huneault, M. A. Hydrolysis of Polylactide in Aqueous Media. J. Appl. Polym. Sci. 2016, 133 (44), 44152.

(36) Narayanan Krishnamoorthy, A.; Holm, C.; Smiatek, J. Specific Ion Effects for Polyelectrolytes in Aqueous and Non-Aqueous Media: The Importance of the Ion Solvation Behavior. Soft Matter 2018, 14 (30), 6243-6255.

(37) Miao, H.; Stephan, I.; Dimke, T.; Cataldo, V. A.; Antonietti, M.; Guterman, R. Thioimidazolium Salts as a Platform for Nonvolatile Alkylators and Degradable Antiseptics. ACS Sustainable Chem. Eng. 2018, 6 (11), 15434-15440.

(38) Chudoba, R.; Heyda, J.; Dzubiella, J. Tuning the Collapse Transition of Weakly Charged Polymers by Ion-Specific Screening and Adsorption. Soft Matter 2018, 14 (47), 9631-9642.

(39) Hofmeister, F. Zur Lehre von Der Wirkung Der Salze. NaunynSchmiedeberg's Arch. Pharmacol. 1888, 25 (1), 1-30.

(40) Moghaddam, S. Z.; Thormann, E. The Hofmeister Series: Specific Ion Effects in Aqueous Polymer Solutions. J. Colloid Interface Sci. 2019, 555, 615-635.

(41) Schwierz, N.; Horinek, D.; Sivan, U.; Netz, R. R. Reversed Hofmeister Series-The Rule Rather than the Exception. Curr. Opin. Colloid Interface Sci. 2016, 23, 10-18.

(42) Aoyagi, N.; Endo, T. Synthesis of Five- and Six-Membered Cyclic Guanidines by Guanylation with Isothiouronium Iodides and Amines under Mild Conditions. Synth. Commun. 2017, 47 (5), 442448. 